\title{
Impact of Social Networking Sites in Bangladesh: Few Possible Solutions
}

\author{
Md. Omar Faruq \\ Department of Computer Science and Engineering, Bangladesh University of Business and Technology, Mirpur-2, \\ Dhaka-1216, Bangladesh \\ E-mail: omarfaruq.cse.bubt@gmail.com
}

\begin{abstract}
Alim-Al-Reza
Department of Computer Science and Engineering, Bangladesh University of Business and Technology, Mirpur-2, Dhaka-1216, Bangladesh

E-mail: reza.cse.bubt@gmail.com
\end{abstract}

Md. Mahbubur Rahman

Department of Computer Science and Engineering, Bangladesh University of Business and Technology, Mirpur-2, Dhaka-1216, Bangladesh

E-mail: mahabub.cse.buet@gmail.com

Mohammad Raisul Alam

Department of Computer Science and Engineering, Bangladesh University of Business and Technology, Mirpur-2, Dhaka-1216, Bangladesh

E-mail: ralam02@gmail.com

\begin{abstract}
Bangladesh is a developing country. But in few recent years this country is going to be turned as digitalized. The first condition of being digitalization is the whole communication system of the country have to be developed tremendously. If we notice about the communication system, then Social Networking Sites can be a platform of revolution. This study is based on the perspective of Bangladesh on Social Networking Sites(SNS). In Bangladesh, Social Networking Sites are getting popular tremendously. The Social Networking Sites(SNS) like twitter and Facebook gives people in general the useful platform for disclosure of their thinking and ideas. This research paper is made with an aim to represent the positive and negative impact of Social Networking Sites(SNS) and we will also try to recommend few possible solutions to overcome these problems.
\end{abstract}

Index Terms-Social Networking Sites (SNS), Cybercrime, e-Learning, Socialization.

\section{INTRODUCTION}

Social networking site has become the world's most popular online social venue where many people, especially the youth, have been spending significant amount of time socializing with their networks of friends [8]. As the use of social network sites rise in popularity, the youth spends large amounts of their time browsing the Internet and interacting via social network sites [9]. Every day new users join SNS, while existing users make new friends or end social connections, join or leave groups, and so on [12]. It is thus important to be aware of the effect that this use has on their sociological and psychological development [9]. We have also found from another study that total number or internet user in Bangladesh is $21,439,070$ people. So here are also few problems with the internet user in Bangladesh. Many social networking sites (i.e., Facebook, Twitter, Instagram, and Snapchat) have responded to the call for prevention and intervention of online abuses and launched built-in functions on their platforms [8]. Connecting through social networks started as a niche activity, but with time it is now a phenomenon [6]. The social networking sites are being used in various ways like forming communities, chatting, blogging etc. Apart from that different institutions even nowadays are forming communities or groups on different Social Networking Sites [6]. Though most of people uses well as survey study. This paper will also give few possible solutions to overcome those problem as well as we have tried to give some recommendation to resolve this affect and minimize the effect. internet on the purpose of browsing social networking site but there are also going through the educational site, e-commerce site, various site of entertainment, blogging site and so on.

\section{RELATED WORK}

There are several Social Networking Sites(SNS) that people are using in Bangladesh. Most of the people use the social networking site by their cell phone [1]. The 
increased use of Social Networking Websites has become has most phenomenon in Bangladesh. A social network is a set of people or groups of people with some pattern of contacts or interactions between them. The patterns of friendships between individuals, business relationships between companies, and intermarriages between families are all examples of networks that have been studied in the past [13]. What started out as a hobby for some computer literate people has become a social norm and way of life for people from all over the world [6]. Several studies have reported positive affordances of Social Media for teaching and learning [10]. Most of these studies are reviews that synthesize findings on the use of Social Media tools, largely in higher education. With reference to microblogging services [11], for instance, pointed out how microblogging has a potential to encourage participation, engagement, reflective thinking, collaborative learning, and to expand learning content in different formal and informal learning settings. There are several Social Networking Sites(SNS) using in Bangladesh. The evaluation of using social networking sites after 2006. Recently huge pollution in Bangladesh use social media via cell phone, tablet, personal computer etc. but there are few drawback using social media that we cannot think. Teenagers and young adults have especially embraced these sites as a way to connect with their peers, share information, reinvent their personalities, and showcase their social lives [6]. With the increase of technology used for communicating with others and the popularity of the Internet, "Social Networking" has become an activity that is done primarily on the Internet, with sites like Myspace, Facebook etc. [6]. An everincreasing growth rate of SNS not only calls for the maternal and teacher monitoring of student users but also attracting the focus of academicians and researchers towards this main incident. Student's use of social networking continues to create challenges and issues for higher education professionals and keeping abreast of these challenges has proved difficult because of the speed at which new technologies are being introduced [10]. According to nternetlivestats.com on Bangladesh basis, $13.2 \%$ (Penetration (\% of pop)) access internet. This study also showed that approximately half of all teens who have Internet access are also members of social networking sites, and use the Internet to make plans and socialize with friends [7]. Social networking sites (SNSs) have attracted attention as network services in organizations [22]. More and more companies such as IBM or Microsoft make use of social media in order to search for and recruit new employees [17]- [20]. There is a tremendous increase in professional company profiles on LinkedIn, XING and similar career-oriented online social network sites (CSNS) [16].

\section{METHODLOGY}

This paper contains basically positive and negative impact on SNS. This paper will discuss the effect of social networking site(SNS). To complete the study at the beginning theoretical analysis is done in all concern on
SNS. Then we have taken sample data in various range of population. The sample data include the people of different age including adult, teen age people and women. The people those are chosen for sample data are in from different occupation and organization to make the survey as well as research more versatile. From the gathered data, we have made the data analysis. Comparing the result as well as few possible solutions is given to minimize and solve the negative impact of SNS in Bangladesh.

\section{EFFECT ON SOCILA NETWORKING SiTES (SNS)}

In recent years, using of social networking sites increasing tremendously. Everyday a lot of new users open account on social networking sites. In modern communication depend on social networking sites. There are few positive and negative effect on social networking sites. we face to advantage of social networking sites. A lot of advantage of social networking sites. Even in modern life we cannot think about a single day without social networking sites. we about familiar law of sir Isaac Newton "Every action has some reaction". According to law if technology is more advanced that has some drawback. We cannot think about the drawback of social networking sites. In our study, we highlight some special drawback of social networking sites. we give some possible recommendation to solve the problem. Now discussing the positive and negative effect on social networking sites.

\section{A. Positive effect on social networking sites (SNS)}

With the development of Social Networking Sites(SNS) such as Facebook, Twitter, Instagram, LinkedIn, Skype, Flicker \& so more that change our modern lifestyle. Using SNS benefited several ways. Some important benefited area is listed-

\section{B. Promoting and aid communication}

SNS has changed drastically changed how we communicate. Not too long age, we communicate others via mail, telephone, telegram, letter. Nowadays we send voice massage, send text, send audio/video call etc. by using social media. All types of online communication are not most efficient now, with email being a near to momentary version of the paper letter; webcams using paired with communication programs such as Skype, iChat or Google Video Chat, make it come to closer by seeing the person you are speaking with rather than just hear his voice. It has been easier to make friends. So, one user communicates others user any time anywhere in the world.

\section{Sharing knowledge and e-learning}

Knowledge discovery, knowledge sharing and collaboration are becoming more important today. With the growing social technologies like blogs, wiki, micro blogs, Facebook, twitter are being used widely in our daily life's and these technologies are now being used by the teaching community to broadcast and deliver lectures to the students at large [7]. Some steps in knowledge 
sharing for students and teachers are [7]

1) Use knowledge sharing to share and broadcast the information and publish to social networking websites.

2) Collaborate knowledge mapping and the elearning system to impart extrinsic knowledge stored as a Learning Object inside the E-Learning tool to social.

3) Create Groups on social sites using either elearning tool or using knowledge management system sites.

4) Design Time table and publish on social networks.

5) Search for any topic of interest related to the course and add it to your social page and publish to the group with the help of knowledge metadata repository

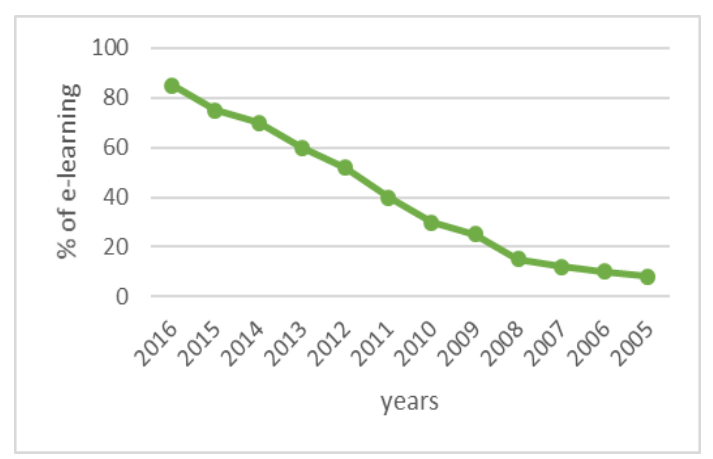

Fig.1. E-learning in Bangladesh

The Fig. 1 shows that $\%$ of e-learning perfective of Bangladesh. The Bar chart shows that years of 2005 to 2016. In 2005 the e-learning probability is only 8\%. The revelation of Social Networking Sites(SNS) started may be in 2006. The increasing of Social Networking Sites that is why the effect on e-learning tremendously. Many online groups have connected different world users. So, communication is easy for helping others. In 2016, the elearning rate increased $85 \%$. It has huge change in Bangladesh.

\section{Effect on businesses}

Social networks have become an essential part daily life. We do not focus when I open our desktop, laptop, smartphone, tablet and so more to access the web, we first open social networks sub-consciously. We see update status when passing our timeline. In business policy, some businessman used social networks primarily because reducing cost of advertise. If one advertise perform of the product, then the cost of advertise is high but in particularly they advertise on social networks free cost. So, social networks are mostly popular for business purpose recently. That is why, small business become popular to higher business. For branding product, they post on video of the specific product. The social networks users show the video when passing on social media, its attracted to buy the product. Some older users use social networks for online shopping.

\section{E. Effect on socialization}

Social networks provide the opportunity for people to recommunicate with their old school or college or university friends, making new friends, sharing post and pictures and so many others activities. Users can communicate locally or globally. They can share personal opinion. One users communicate to other global friends when they know about culture on society. Students can participate with their peers to improve their academic proficiency and communication skills. So, the interaction between the students and teachers are good. Suppose we face one problem in late night then we knock to others via social networks, they can have suggested to some few possible solutions. Several users use social networks different purpose. LinkedIn used for creating to enhance professionals career and business purpose.

\section{F. Negative effects on social networking sites (SNS)}

Large number of people in the world connected anyhow on social networking site(SNS). social networking site(SNS) deploy our society in different way. Suppose SNS aid amelioration of our life but do not thinking how destroy our environment \& life. Now discussing some negative impact on social networking sites.

\section{G. Effect on child and teenager}

Social networking sites have greatly subjugated and affected the minds of teenager today's life. The most common bad effect of social media is addiction - the continuously checking of Facebook, Twitter, or other social media updates status. When technology misuse checks their device very often its addiction damage human brains. For kids and teens, this devotion could throw into confusion other valuable activities like centralizing in schoolwork, reading or attractive in sports. Facebook and other social media are infantilizing the brain into the state of small children who are attracted by scurry noises and bright lights, who have a short attention spread and live for the moment. Pediatricians accomplish that some teenager suffers from Facebook depression. After passing a lot of time on Facebook and other popular social networking sites, some teenager become concerned and depressed. They attracted virtual life then real life. If parents are connected with their children's social media activities, their children are less possibly to be upset with what befall to them online. Now a days Children pass more time in the family home lonely in front of TV/computer screens than doing anything else. Cyberbullying has occurred that the main issue for teenagers in recent years. In some well circulated cases, victims might be wielded to suicide. The anonymity afforded online could bring out dark impulses which may otherwise be subdued. Because the Internet unauthorized students to remain anonymous on websites or create fake profiles, cyber-bullying has become a significant issue that many children between the ages of 6 to 17 have indicated victims of cyber-bullying more 


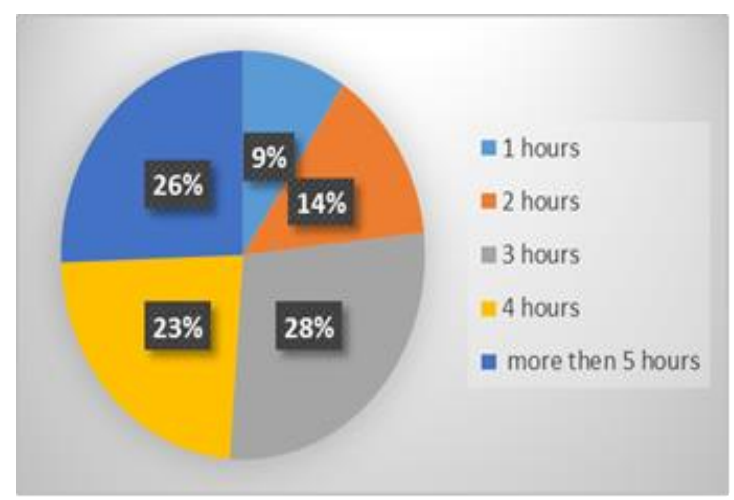

Fig.2. Child time spending on SNS daily

The pie chart shows that more than 3 hours use SNS daily. So, child is addicted on SNS. Child are trusted on virtual life then real life. Long time spending on SNS, their academic performance damage.

\section{H. Damaging mental \& physical health}

In our survey analysis, one-person access more than 4 account that is $37.3 \%$ up. Everybody know about cancer. Long-time using every day that cause cancer. Using social media face-to-face contacts with friends and family are being recapture by face-to-screen isolation, and how the lack of real-world social interaction can rise your sensitivity to cancer, influenza, diabetes, dementia, heart diseases, rheumatoid rheumatism, lupus, even the common cold so on. social isolation can influence the level to which genes are abuzz in white blood cells.

\section{Losing revenue via illegal use of social networking sites (SNS)}

In modern civilization, social media access for marketing strategy. Most of them people spend time using social media. Many originations use social media for rising familiarity. Before any movies/songs released using CD/DVD but now a day that cannot found. That is why they losing revenue. most of profit take the owner of social media. Many e-commerce site doing business via social media. Some user advertises on SNS their product then connect client via barter contact number\& buy essential things. Finally, loss the revenue of ecommerce business of illegal use of SNS. Understanding companies are using social media to asserting their products, build customer faith and many other functions. Interactions and recompose from customers help businesses to grasp the market, and better their products and strategies.

\section{J. Losing privacy when share or status on personal information}

This is probably the biggest unsatisfactory impact that social networking as a whole is having on society. Hackers love social networking, going right to the source to insert malicious code. Sometimes hackers go right to the source, inserting malicious code into a social networking site, including within advertisements or via third-party apps. On Twitter, URLs can be used to trick users into observing malicious sites that can extract personal information if obtained through a work computer. Twitter is especially vulnerable to this method because it's easy to retweet a post so that it could be seen at last by hundreds of thousands of people. Downloading your videos or pictures and copying your status is an easy an important task and can be committed within few clicks. Especially victim girls/women. They can share video/photo via social media. Hearing almost these photo/video hack. Some people harass them. Some people download anonymous photo and open feck account using these photos. Many occurrences happen these feck account. Sharing feck news via social media that deploy the original people. SNS have been widely used by men for creating sexual abuse against women, especially juvenile girls. It is widely reported that during a relationship juvenile girls are often victimized by men taking photos/videos of private moments. Some teens girls and boys who sent or posted sexually inspiring content say they sent it to a boyfriend or girlfriend. Some of kids ages 8-18 have in course of circumstances encountered online pornography page when use social media.

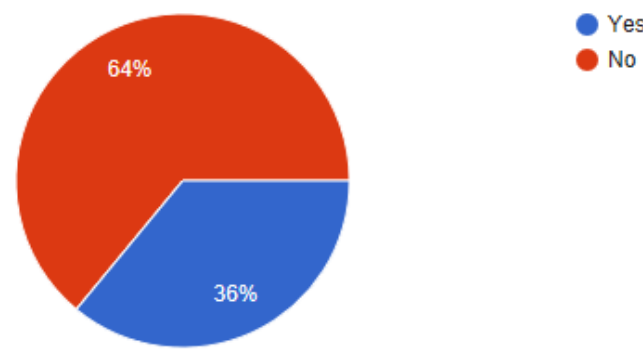

Fig.3. Security purpose of sharing information on SNS

$80 \%$ people share fillings on SNS. They share but not trust on SNS sites. Many cybercrimes occur for that reasons.

\section{K. Cybercrime using SNS}

In survey analysis about $33.2 \%$ user affecting in cybercrime. Although, SNS is new stage of cybercrime. In Bangladesh, major part of people using Facebook for illegal purpose. Facebook, a social networking site, has become a major basis for criminals to carry out their operations. These days, many hackers open up fake accounts on Facebook and spread humiliating pictures and insidious information to other users. They also steal personal fact, pictures and contact information of other users. Some criminals take pictures or gather pictures from Facebook of female students and then writing blogs to reveal or distribute the pornographic content in Facebook to harass them. According to the media, many victims keep quiet to eliminate embarrassment and a few become mentally imbalanced. Many crimes are taking place by using social networking sites. Crafting people are setting trap and who are new in this virtual world fall there. Due to lack of having knowledge about social media it happens. But sometimes it's too much dangerous for individual or a group of people. That is way govt. of Bangladesh stop all SNS for privacy. In this case, several user use SNS illegally like VPN, proxy internet 
protocol(IP). In survey analysis, take a question about cybercrime. The question is "Do you face any cybercrime when using social media?". We found that $60 \%$ user face cybercrime using SNS.

\section{Ffecting human behaver using long time spend per day}

When you're on a social media site like Facebook, Twitter, you show a lot of posts people perform different tasks. That sets up social discrimination that you may be release your life is not as full and rich as those people you see on Facebook. Social media main cause for depression like showing intimate post. Many users use social media as addiction. Truly saying that social medial can let you be habit-forming. One of the negative effect of social media or network is its guidance to addiction. Spending more than 4 hours per day on the social sites can disarticulate the focus and attachment from a particular task. As written above, comments and likes on Facebook can encouraging your self-esteem, but in some cases, it also attacks negatively your self-esteem, too. Particularly, they singled out the blow to their self-esteem that comes from find a simile for themselves to equal on Facebook and Twitter as the greatest degeneration.

\section{Effects on relationships via social networking sites} (SNS)

Another vital way that social media influence its users' network of relationships is with the help of how it simulates romantic relationships. In survey analysis findings, have shown that Facebook can be making mischief to romantic relationships due to increased jealousy, partner surveillance, and captivating internet use. And unhappily, not getting along with one's spouse was related to more mental disorders than not getting along with relatives or friends. Internet use in general, not just social media use, has been displayed to influence romantic relationship quality negatively. However, this jealousy can happen in online connection as well as in offline ones investigate the relationship interim Facebook use and jealousy and found that individuals who pass more time on Facebook indicated more jealousy within romantic relationships and increased controlling of their romantic partner's Facebook profile

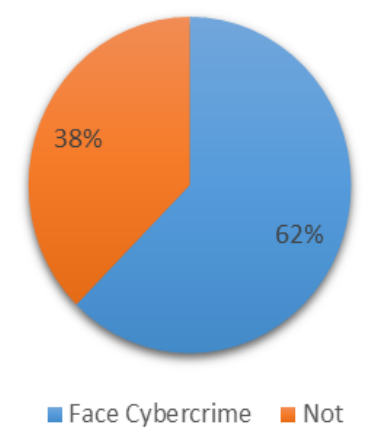

Fig.4. Facing Cybercrime Using SNS

\section{DAta ColeEction}

In our study, we have made some questions based on Social Networking Sites(SNS). The question form is prepared in google form to find our data. This is the main process of collecting data. Finally, we share the google form link and user fill up the form. In our survey, we have found 1400 people opinion as data. Most of them are found as the university going students. we also have done the same survey on schools, colleges and job holders people. Through our survey, we have achieved some result by analyzing data that is being done on data analysis part.

\section{SURVEY ANALYSIS RESUlT}

In data analysis section, we will show an over view of the data that we have acquired from our survey as well as we will give some comparison of the data that have been achieved by conducting survey on activities of cell phone with the people including youth and women, internet user and also on the social networking site user in Bangladesh. The graphical representation of data and the table will help the reader to understand our survey result more easily. The below graph will show the graphical representation of social networking site (SNS) user in Bangladesh. This is based on our survey data that was done to 1400 people as sample data. That will show the behavior of social networking site user in Bangladesh. Here we have added all the social networking site (SNS) that Bangladeshi people use.

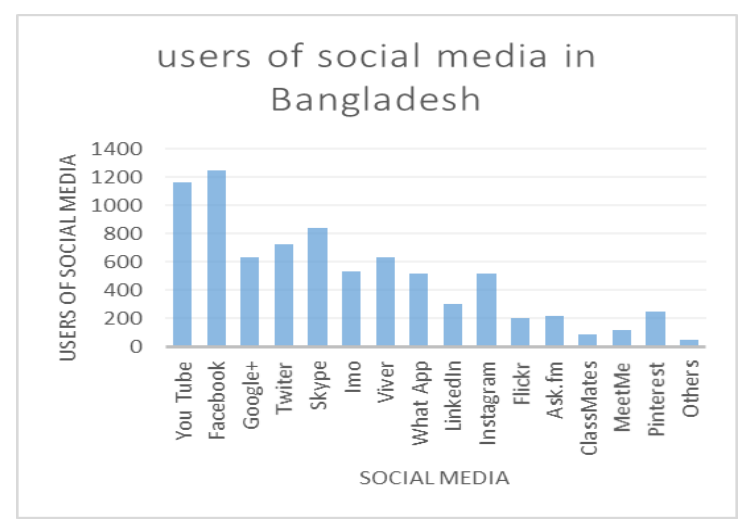

Fig.5. Users Social Networking Sites(SNS)

Table 1 shows that users of social media in Bangladesh the internet user of Bangladesh is growing up rapidly. According to Wikipedia Bangladesh is in 9th position in all over the world according to the number of internet user. Hence, we gave gathered some data on the below table will show about the over view of using internet in Bangladesh since 2005 to May, 2016 source form internetlivestats.com. 
Table 1. Internet User in Bangladesh

\begin{tabular}{|c|c|c|c|c|}
\hline Year & Internet user & Penetration (\% of pop) & 1Y User Change & Population change \\
\hline 2016 & $21,439,070$ & $13.2 \%$ & $10.4 \%$ & $1.19 \%$ \\
\hline 2015 & $19,420,674$ & $12.1 \%$ & $27.2 \%$ & $1.21 \%$ \\
\hline 2014 & $15,271,441$ & $9.6 \%$ & $46.6 \%$ & $1.22 \%$ \\
\hline 2013 & $10,419,535$ & $6.6 \%$ & $34.2 \%$ & $1.22 \%$ \\
\hline 2012 & $7,762,869$ & $5 \%$ & $12.5 \%$ & $1.21 \%$ \\
\hline 2011 & $6,903,253$ & $4.5 \%$ & $23.1 \%$ & $1.18 \%$ \\
\hline 2010 & $5,609,821$ & $3.7 \%$ & $20.7 \%$ & $1.14 \%$ \\
\hline 2009 & $4,647,081$ & $3.1 \%$ & $25.4 \%$ & $1.12 \%$ \\
\hline 2008 & $3,706,312$ & $2.5 \%$ & $40.5 \%$ & $1.13 \%$ \\
\hline 2007 & $2,638,668$ & $1.8 \%$ & $82.2 \%$ & $1.21 \%$ \\
\hline 2006 & $1,448,392$ & $1 \%$ & $319.4 \%$ & $1.34 \%$ \\
\hline 2005 & 345,372 & $0.2 \%$ & $23.2 \%$ & $1.48 \%$ \\
\hline
\end{tabular}

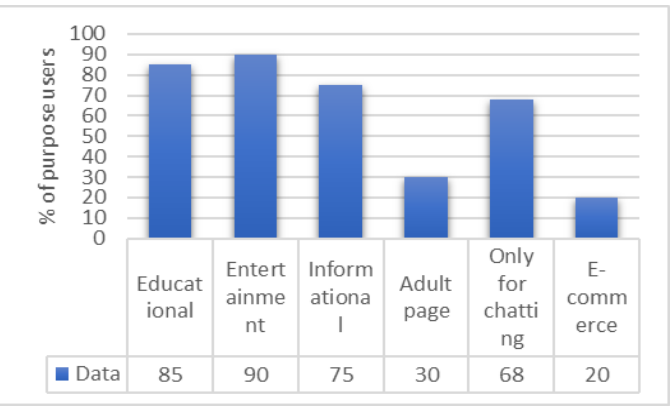

Fig.6. Purpose of using SNS among various people

The Fig. 6 represent why we can use social networking sites. The figure shows that many of user use social networking sites for entertainment. The second is educational purpose. Many user use SNS for getting information. Some user uses social networking sites only for chatting opposite people or same people. The survey found that social networking sites used badly for student performance or hampered for wasting time.
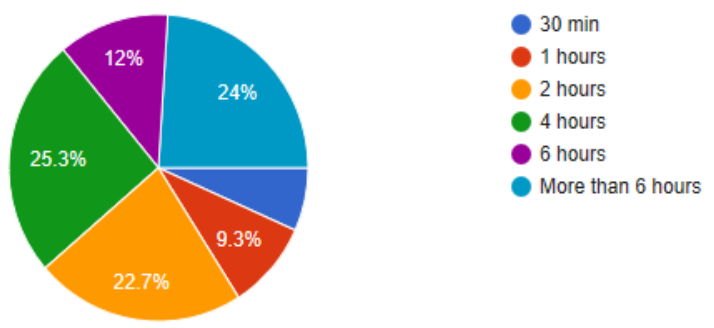

Fig.7. Time Spend in Social Networking Sites(SNS) per day

The Fig. 7 illustrate about time spend on Social Networking Sites (SNS) per day. $25.3 \%$ users use SNS 4 hour. There are numerous malicious accounts in SNS and use these accounts.

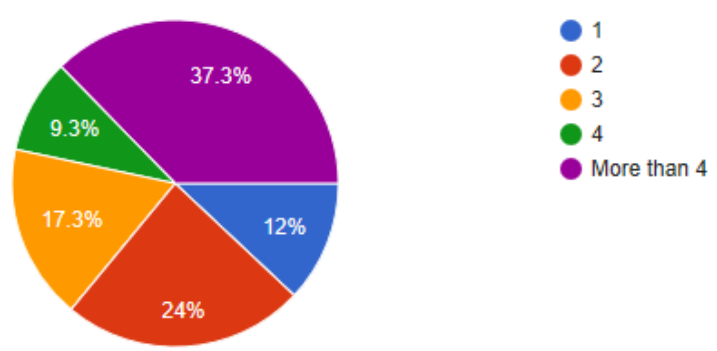

Fig.8. Social Networking Sites (SNS) account of one person.
$37.3 \%$ people use more than four Social Networking Sites such as Facebook, Twitter, YouTube and Google+ etc.

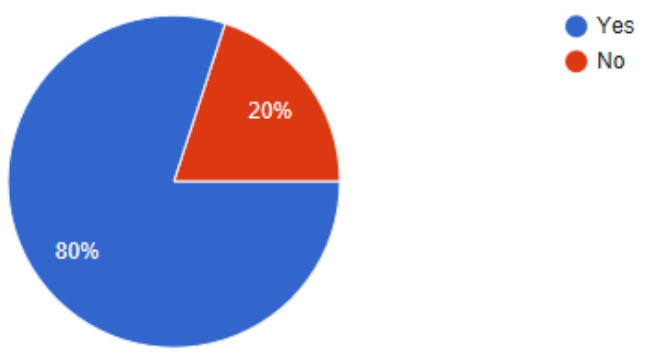

Fig.9. Expressing ideas and feelings on Social Networking Sites(SNS).

Almost $80 \%$ people share activity via SNS. People

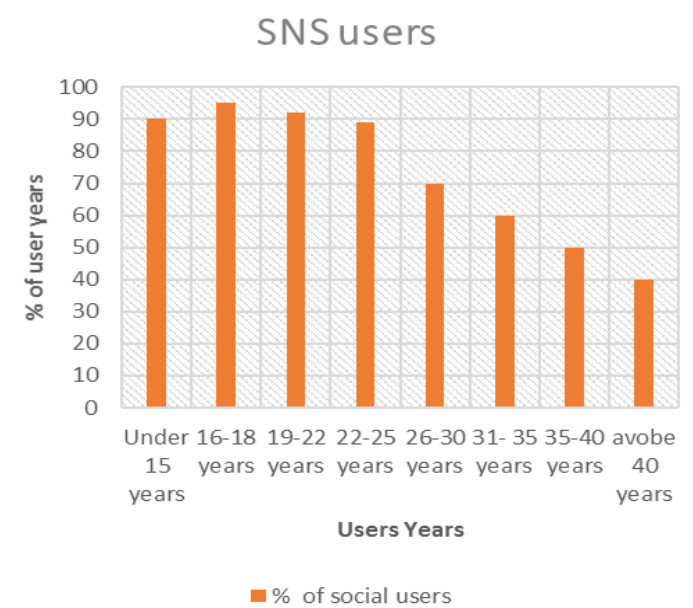

Fig.10. Considering by ages increasing $\%$ of user year by year

The Fig. 10 shows that 16 to 18 users more. But a lot user under 15 . Some user open account does not verify by age. That is why people open account easily and engaged illegal work. 


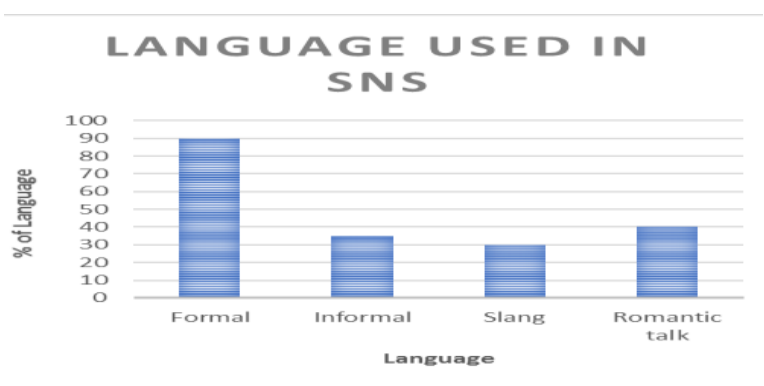

Fig.11. Which language is preferable to use in SNS

The Fig. 11 represent that what type of language used when chatting, posting, comment etc. In survey data found that formal language can be used more.

\section{Recommendations}

In this problem, there is no mathematical solution. Only the ethical solution possible. One of the best solution of social networking sites is limiting their access to social networking and also diminution of the amount of time spent on social network sites. provide roomy time for face to face social connection, like having some family lecture time in which you discuss their studies in a relaxed atmosphere. Some possible recommendations are-

- Be careful about the information you importing online, like if you give your photo or video or your account details will stay for a long time and who joint in your social media account will see it. Sometimes attackers may morph your photo and may misuse them.

- If you want to fall on a social networking friends in person, think before you fall on, it may not be true similarity posted on a web site. If you are going to fall on, then inform to your parents and do it in a public place during the day.

- Remember do not put anything personal like sensorial information about your family details, addresses, personal photographs or snapshots they might be misused.

- Block apps and sites that snoop. Unless you intercede, sharing personal information via these apps. To block that apps, using monitoring to limit the info apps can see to opposite enemy.

- Think before you type: Even if you delete your personal account (which takes Facebook about a month), some info can be keeping in Facebook 's server for up to 90 days.

- Mostly, girls face vexation in social media. There is a group of mentally disorder young boys who intentionally disturb unknown girls. Even known girls also. Those boys take the photos of girls and create imitation account and do evil work with people. Even boys or adult man sexually harasses girls. So, thinking about whose people before this problem.

- If some hacker add request to contract from unknown id, then you add your contact list when your personal information stolen. users don't know the unknown id how much reliable. This one of main drawback of social media.

- May apps shows several funny comments. We cannot think that, those apps when inserting our social media account, ours account related all information putting those apps. Those apps access ours account. So, careful about apps.

- Many accounts cannot have verified by age. Just like as Facebook account open when age is 13 or up but some people use social media when age is not. So carefully identify the account is valid or not be consideration on age.

- Many social networking sites used spell check on grammar. That is why the depend on spell check. So, writing efficiency can be reduced. So, limiting use of social networking sites

\section{CONCLUSION}

With the touch of modern science Bangladesh is getting digitalized day by day. As a result, we have some changes in Social networking sites that are influencing positively and negatively to the people of Bangladesh. This paper contains an over view of positive and negative impact of SNS. As it clear to everybody that without social networking site digitalization is not possible at all. So, we have to filter the system as we are just in the beginning of the digitalization. The discussed problems are most of the case in primary condition, it can be solved if the given solution is applied properly. But if it is not then the negative impacts o SNS will be expanded day by day. As result SNS never will be able to go on that destination for why it was being developed. If in some case it not possible to completely solve the negative impact where our recommendation will help to minimize the effect.

\section{REFERENCES}

[1] Alim-Al-Reza, Md. Omar Faruq, Md. Mahbubur Rahman, "Impact of Cell Phone in Bangladesh: Possible Solutions", in International Journal of Science and Research (IJSR), Vol. 05, Issue 12, 2016.

[2] Amelia, c. strickland, "Exploring the effects of social media use on the mental health of young adults", PP. 1-55, 2014- University of Central Florida

[3] M. Owusu-Acheaw, Agatha GiftyLarson," Use of Social Media and its Impact on Academic Performance ofTertiary Institution Students: A Study of Students of Koforidua Polytechnic, Ghana" Journal of Education and PracticeVol.6, No.6, 2015.

[4] Arafatur Rahaman, G. M. Shafayet Ullah,'Exploration of Influencing Factors That Effecting Facebook Privacy Awareness On Bangladeshi Undergraduate University Student 's"”, pp. 163-171, June 2013International journal of scientific \& technology research .

[5] Thawhidul Kabir, Shirin Akter, ZannatulFerdus, "Exploitation of Social Networking Sites and Its Impacts on Students' Academic Results: A Quest for Correlation or Misspecification in Bangladesh", Journal of Business and Technology (Dhaka) Volume-IX, Issue-01, JanuaryJune, 2014. 
[6] Saba Mehmood, Tarang Taswir, "The Effects of Social Networking Sites on the Academic Performance of Students in College of Applied Sciences", pp. 111-125, January-2013-International Journal of Arts and Commerce.

[7] Ahsan Ahmed, Ahmad Raza Khan, Sultan Ahmed, "Collaboration of Knowledge Network and E-Learning System with Social Sites for Teaching-Learning”, pp. 147 - 150, 27-29 Aug. 2014- IEEE.

[8] Randy Y.M. Wong, Christy M.K. Cheung, Bo Xiao, "Combating Online Abuse: What Drives People to Use Online Reporting Functions on Social Networking Sites", pp. 415 - 424, 5-8 Jan. 2016-IEEE.

[9] Petra le Roux, Marianne Loock, "The Impact and Opportunities of eTutoring in a Challenged SocioEconomic Environment", pp. 1 - 6, 4-5 Dec. 2015-IEEE.

[10] Stefania Manca, Maria Ranieri "Facebook and the Others Potentials and obstacles of Social Media for teachingin higher education", pp. 216- 230, April 2016sciencedirect.

[11] Gao, F., Luo, T., \& Zhang, K. (2012). Tweeting for learning: A critical analysis of research on microblogging in education published in 2008- 2011. British Journal of Educational Technology, 43, 5, 783-801.

[12] L. Jin, Y. Chen, T. Wang, P. Hui, A. V. Visalakos, "Understanding User Behavior in Online Social Networks: A Survey”, IEEE Communication Magazine, September 2013, pp. 144-150.

[13] Md. Mehedi Hasan, Noor Hussain Shaon, Ahmed Al Marouf, Md. Kamrul Hasan, Hasan Mahmud, and Md. Mohiuddin Khan, "Friend Recommendation Framework for Social Networking Sites using User's Online Behavior", IEEE- Computer and Information Technology (ICCIT), December 2015, pp. 539-543.

[14] Md. Mahbubur Rahman, "Impacts of ICT to Health and Environment: A review of bad effect of ICT in recent time", December 2011- The ACM Digital Lib

[15] Christopher H. Ruehl; Diana Ingenhoff, "Community Management on Social Networking Sites: Why and How Stakeholders Use Corporate Facebook Pagesrary", IEEEHawaii International Conference on System Sciences (HICSS), pp 2216 - 2226, 2016.

[16] Ricardo Buettner, "Getting a Job via Career-oriented Social Networking Sites: The Weakness of Ties" IEEEHawaii International Conference on System Sciences (HICSS), pp. 2156 - 2165, 2016.

[17] R. Doherty, "Getting social with recruitment," Strategic HR Review, vol. 9, no. 6, pp. 11-15, 2010.

[18] S. A. Madia, "Best practices for using social media as a recruitment strategy," Strategic HR Review, vol. 10, no. 6 , pp. 19-24, 2011.

[19] X. Zhou, Y. Xu, Y. Li, A. Josang, and C. Cox, "The stateof-the-art in personalized recommender systems for social networking," Artificial Intelligence Review, vol. 37, no. 2, pp. 119-132, 2012.

[20] R. Buettner, "A Systematic Literature Review of Crowdsourcing Research from a Human Resource Management Perspective," in HICSS-48 Proc., 2015, pp. 4609-4618.

[21] Rami Belkaroui; Rim Faiz; Aymen Elkhlifi, "Conversation Analysis on Social Networking Sites", IEEE-International Conference on Signal-Image Technology \& Internet-Based Systems, pp. $172-178$, 2014.

[22] Namie Kato; Hirohiko Suwa; Toshizumi Ohta; Satoshi Kurihara, "User Survey on Introducing Social Networking Sites into Enterprises", SICE Annual Conference, pp. $1226-1236,2014$

\section{Authors' Profiles}

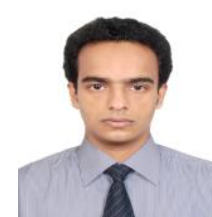

Md. Omar Faruq is an undergraduate student of Computer Science and engineering department in Bangladesh University of Business and Technology. Currently he is doing research in Ad-hoc Network. His others research interested areas are: Machine Learning (ML), Human Computer Interaction (HCI), Neural Network, Internet of things (IOT), Network Security, Biometric System and etc.

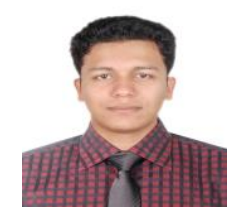

Alim-Al-Reza is an undergraduate student of Computer Science and engineering department in Bangladesh University of Business and Technology. Currently he is doing research in Ad-hoc Network. His others research interested areas are: Machine Learning (ML), Human Computer Interaction (HCI), Neural Network, Internet of things (IOT), Biometric System and etc.

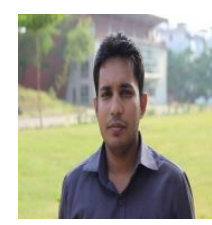

Md. Mahbubur Rahman received his B.Sc. engineering degree in Computer Science and Engineering (CSE) from Patuakhali Science and Technology University (PSTU), Bangladesh, in 2011. He has completed his M.Sc. engineering degree in CSE at Bangladesh University of Engineering and Technology (BUET), Bangladesh and working as an Assistant Professor in CSE at one of the top most private universities in Bangladesh named Bangladesh University of Business and Technology (BUBT). His research interests are data mining, search engine optimization, biometric system, network Security.

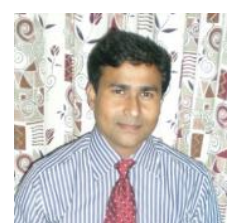

Mohammad Raisul Alam received his B.Sc engineering degree and M.Sc. in Computer Science and Engineering with distinction result. Now working as an Assistant Professor in CSE at one of the top most private universities in Bangladesh named Bangladesh University of Business and Technology (BUBT). His research interests are data mining, search engine optimization, biometric system, Neural Network, Software Engineering and etc.

How to cite this paper: Md. Omar Faruq, Alim-Al-Reza, Md. Mahbubur Rahman, Mohammad Raisul Alam,"Impact of Social Networking Sites in Bangladesh: Few Possible Solutions", International Journal of Intelligent Systems and Applications(IJISA), Vol.9, No.4, pp.53-60, 2017. DOI: 10.5815/ijisa.2017.04.06 